January 2013

\title{
The sociodemographic and health-related characteristics of a regional population with chronic disease at an interprofessional student-assisted clinic in Queensland Capricornia Allied Health Partnership
}

Kerrie-Anne Frakes

Central Queensland Hospital and Health Service

Sharon Brownie

Aga Khan University, sharon.brownie@aku.edu

Lauren Davies

Queensland Health

Mary-Ellen Miller

Griffith University

Zephanie Tyack

The University of Queensland

Follow this and additional works at: http://ecommons.aku.edu/eastafrica_fhs_sonam

Part of the Nursing Commons

\section{Recommended Citation}

Frakes, K., Brownie, S., Davies, L., Miller, M., Tyack, Z. (2013). The sociodemographic and health-related characteristics of a regional population with chronic disease at an interprofessional student-assisted clinic in Queensland Capricornia Allied Health Partnership. Australian Journal of Rural Health, 21(2), 97-104.

Available at: http://ecommons.aku.edu/eastafrica_fhs_sonam/75 


\title{
Original Research
}

\section{The sociodemographic and health-related characteristics of a regional population with chronic disease at an interprofessional student-assisted clinic in Queensland Capricornia Allied Health Partnership}

\author{
Kerrie-Anne Frakes, BAppsci (Pod), B BioMed Sc, Grad Dip Wound Care, ${ }^{1}$ \\ Sharon Brownie, DBA, M Hlth S Mgt, M Ed Amin, B Ed, RM, RN, ${ }^{2,4}$ \\ Lauren Davies, BA Hons (Psych), MOrgPsych, ${ }^{3}$ Janelle Thomas, BSc, PhD, ${ }^{2}$ \\ Mary-Ellen Miller, BA Hons Psyc, MAppPsyc, PhD, ${ }^{3,4}$ and \\ Zephanie Tyack, B Occ Thy (Hons.), PhD ${ }^{1,5}$ \\ ${ }^{1}$ Central Queensland Hospital and Health Service, Queensland Health, Rockhampton, ${ }^{2}$ Clinical \\ Education and Training Queensland, Queensland Health, ${ }^{3}$ Siggins Miller Consultants, Brisbane, \\ ${ }^{4}$ Griffith University, Gold Coast, ${ }^{5}$ School of Health and Rehabilitation Sciences, The University of \\ Queensland, Brisbane, Australia
}

\begin{abstract}
Objective: This paper describes the sociodemographic and health-related characteristics of people with chronic disease attending an interprofessional student-assisted clinic in regional Queensland.

Design: A retrospective review of data collected during the first 10 months of operation of the clinic was conducted.

Setting, participants and outcome measures: Data was collected on up to 378 patients during an intake appointment at the Capricornia Allied Health Partnership (CAHP) community-based clinic and compared with normative reference groups where available. Sociodemographic characteristics included age, gender and education level; health-related characteristics included body mass index and hospitalisations in the previous 12 months; and risk factors included prescribed medications, smoking status and general practitionerdiagnosed medical conditions.

Results: Patients attending the CAHP clinic had a mean number of chronic conditions of $4.9 \pm 2.1$ per patient, and $97 \%$ of patients had multimorbidities. A high level
\end{abstract}

Correspondence: Ms Kerrie-Anne Frakes, Central Queensland Health Service District, PO Box 501, Rockhampton, Queensland, 4700, Australia. Email: kerrieanne_frakes@health.qld. gov.au

Accepted for publication 6 September 2012. of socioeconomic disadvantage was found in comparison with normative comparison groups based on employment, highest level of schooling completed and the index of social disadvantage. Patients predominantly lived in inner regional areas $(76.7 \%)$. The most common diagnoses of patients attending the clinic for the first time were hypertension, osteoarthritis, high cholesterol, diabetes and chronic back pain.

Conclusions: The CAHP clinic offers a unique studentassisted service model for interprofessional management of patients who are socioeconomically disadvantaged, have multimorbid chronic disease and live in regional areas. The description of baseline data in this paper is important to refine clinic services, to guide other chronic disease clinics and to inform future research study designs.

KEY WORDS: allied health, chronic disease intervention, health outcomes, multimorbidity.

\section{Introduction}

Chronic disease is a major cause of death and disability worldwide. In 2007, chronic diseases were found to be responsible for $88 \%$ of the disability burden using disability-adjusted life years in Queensland. ${ }^{1}$ For the region of Central Queensland, the picture of chronic disease is worse than Queensland overall and Australia. Mortality rates for cardiovascular disease, as well as 
What is already known on this subject:

- People with multimorbidity; those from regional and remote areas; those with high or very high psychological distress; those who are overweight or obese; current smokers; and past hospitalisations are likely to have worse health outcomes and have greater health-related costs than counterparts without these characteristics.

- Describing the characteristics of patients at baseline is important, particularly for groups whose health is likely to deteriorate over time regardless of the intervention.

- Understanding the characteristics of people attending a service can assist in planning and refining service delivery and can inform future research designs.
What this study adds:

- The study adds to the very small evidence base regarding the characteristics of patients seeking allied health and chronic disease intervention in regional Australia.

- The description of a unique interprofessional allied health service provides details on the context of service delivery to inform comparison with other groups.

- Information reported on can guide other chronic disease services and researchers with respect to the patient characteristics that are important to consider when caring for people with a range of different chronic diseases and multimorbidity in the community. rates of people who smoke, who are obese/overweight and who also suffer from asthma and type 2 diabetes are higher in Central Queensland when compared with state and national levels. ${ }^{2}$ Almost two thirds of avoidable hospitalisations in Australia have been attributed to chronic health conditions. ${ }^{2}$ From 2000 to 2001, nearly $60 \%$ of allocated national health expenditure in Australia was accounted for by chronic diseases excluding injuries. $^{3}$

In light of significant allied health workforce shortages to adequately address the increased burden of chronic diseases within the community, the Central Queensland Health Service District (CQHSD) initiated the Capricornia Allied Health Partnership (CAHP) project. CAHP used a student-assisted clinical placement model within a chronic disease service to increase access to prevention and early-intervention allied health services.

The aim of this paper is to describe the sociodemographic and health-related characteristics of patients with chronic disease referred to the CAHP clinic. The data gathered provide a picture of the health of patients at their first attendance to the service (baseline). These data, along with planned short- and medium-term longitudinal studies, will assist in planning future service delivery and research. The importance of documenting the characteristics of chronic disease patients entering a service such as CAHP has been highlighted by studies that have linked patient characteristics to health outcomes and health costs. ${ }^{4,5}$ In addition, understanding the characteristics of people attending a service can assist in planning and refining service delivery. ${ }^{6}$

\section{Methods}

\section{Ethics}

Ethical approval was obtained from the CQHS District (HREC/11/QCQ 19) to include data collected retrospectively between February 2010 and November 2010.

\section{Clinical setting}

At CAHP, allied health students work in an interprofessional clinical environment as part of a third or fourth year student placement, where they deliver allied health outpatient services under the supervision of experienced clinical staff. During the study period, students and clinical staff from the professions of nutrition and dietetics, occupational therapy, exercise physiology, podiatry, pharmacy and social work were included in the clinic, with a student to supervisor ratio of $4: 1$. The average length of student placement over the study period was $5.6 \pm 2.0$ weeks, ${ }^{7}$ with $97 \%$ of students enrolled at a university outside the Central Queensland region. ${ }^{7}$ Students were placed in the clinic for the full 10 months that data were collected in the study, with a total of 73 student placements in the aforementioned professions. ${ }^{7}$

Patients accessed services at the clinic by referral from their general practitioner (GP), or local hospital or by self-referral. Referrals were directed at one or more allied health professions for the management of clients, with conditions including type 2 diabetes mellitus, cardiopulmonary disease, chronic kidney disease, obesity, chronic back pain, chronic venous disease, osteoarthritis and rheumatoid arthritis.

Patient's first contact with CAHP was through a single point intake screening process, where patient's 
baseline functioning was established, the patient's main health concerns were identified and the patient's goals for therapy were sought. Following this, all students and clinic team members discussed the patient's health status and their therapy goals through an interprofessional case conference to develop a case management plan that was presented to the patient for approval. Further to this, the CAHP service provided a range of clinical interventions including a diverse range of profession-specific and interprofessional interventions in line with the agreed patient goals. This included rehabilitation gym sessions as well as individual consultations with the various allied health professions that formed the clinical team. These services were delivered by the students under the guidance of profession-specific supervisors. Patients received a mean of 6.29 occasions of service per referral to the service (mean $6.29 \pm$ SD 7.11, range $1-54)$.

\section{Outcome measures}

A combination of self-report and observer-administered measures was used to collect patient data at intake to the services. The sociodemographic information collected is detailed in Table 1. Self-report measures included the number of prescribed medications in use, the number of hospitalisations in the previous 12 months, psychological distress measured using the Kessler10 $10^{8}$ and smoking status (current, previous, passive or non-smoker). Observer-administered measures included height and weight, used to calculate body mass index (BMI). Multimorbidity was measured by counting the number of GP diagnosed chronic diseases (Table 2).

\section{Procedures}

Students were trained to administer the outcome measures in a standard manner and to provide standard instructions to patients regarding completion of the selfreport measures.

\section{Data analysis}

Descriptive statistics including means and standard deviations, percentages and confidence intervals were used to analyse data. Where possible data were grouped into subgroups to match Australian Bureau of Statistics normative reference data. ${ }^{9-13} \mathrm{Chi}$-square goodness of fit was used to determine the difference between the study population, and local and national normative reference groups for sociodemographic and health-related characteristics. Sample proportions with $95 \%$ confidence intervals were used to analyse the difference in the subgrouping of health-related characteristics between the study population and national normative reference groups, where a reference group was available.

\section{Results}

Patients were referred to the CAHP clinic primarily by GPs, with the most common reasons for referral being diabetes $(40.5 \%)$, cardiac conditions $(18.3 \%)$ and osteoarthritis (18.5\%) (Table 3). The mean age of patients was 56.4 years with a range from 13 to 92 years. Over half of the patients were married $(54.9 \%)$ and had completed grade 10 of secondary school or less $(66.2 \%)$. The largest percentage of patients were retired $(31.3 \%)$, followed by those receiving a disability support pension $(20.9 \%)$. Indigenous patients made up $7.1 \%$ of the sample (Table 1 ). The majority of patients were from inner regional or outer regional areas $(76.7 \%$ and $22.2 \%$, respectively). The majority of patients $(76.7 \%)$ lived in communities of relative socioeconomic disadvantage (Table 1).

Comparison of the sociodemographic characteristics of the study population with a normative reference group indicated significant differences in the characteristics of age, gender, highest level of school completed, employment, remoteness and index of social disadvantage (Table 1).

In terms of health-related characteristics, almost all CAHP clinic patients (97\%) had been diagnosed with multimorbidities. The mean number of chronic diseases for the sample was close to five, with a range of 1-12 (Table 4). The most common diseases reported by GPs were hypertension $(60 \%)$, osteoarthritis $(59 \%)$ and diabetes $(46 \%)$, with $36 \%$ of patients reported to have mental health issues (Table 2). The mean number of prescribed medications was 5.67 ; however, $90 \%$ of patients were taking two or more medications. In addition, almost half $(43.3 \%)$ of the patients were hospitalised during the previous year. The number of hospitalisations in the past 12 months was significantly higher than the national normative reference group ${ }^{13}$ $(P<0.0001)$ (Table 5).

The mean level of psychological distress of the study sample was moderate. A highly significant difference was found between the study sample and the normative reference group $(P<0.0001)$, with a higher proportion of people with moderate to very high psychological distress in the study sample ${ }^{12}$ (Table 6).

Based on BMI measured at intake, $89 \%$ of patients were overweight or obese, with a mean BMI of $35.31 \mathrm{~kg} \mathrm{~m}^{-2}$. There was a significant difference $(P<0.0001)$ in the proportion of patients who were classified as underweight/normal weight, overweight and obese compared with the National Survey of Mental Health and Wellbeing ${ }^{12}$ sample, with a greater proportion of obese people and a lower proportion of 
TABLE 1: Sociodemographic characteristics $\$$

\begin{tabular}{|c|c|c|c|}
\hline & & $\begin{array}{l}\text { Normative reference group: } \\
\text { Census of Population and } \\
\text { Housing (2006) }\end{array}$ & \\
\hline Characteristics & Study number $(\%)$ & Number $(\%)$ & $P$ valueII \\
\hline Age (15-92 years) & $n=377$ & $n=68094 \dagger$ & $<0.0001$ \\
\hline Mean \pm SD $($ range $)=56.4 \pm 14.0(13,92)$ & - & & \\
\hline $15-39$ years & $48(12.7 \%)$ & $24066(35.3 \%)$ & \\
\hline $40-64$ years & $218(57.8 \%)$ & $35157(51.6 \%)$ & \\
\hline $65-92$ years & $111(29.4 \%)$ & $8871(13.0 \%)$ & \\
\hline Gender & $n=378$ & $n=53664 \dagger$ & 0.04 \\
\hline Male & $166(43.9 \%)$ & $26352(49.1 \%)$ & \\
\hline Female & $212(56.1 \%)$ & $27312(50.9 \%)$ & \\
\hline Marital status & $n=377$ & $n=34898 \dagger$ & 0.55 \\
\hline Married & $207(54.9 \%)$ & $25169(72.1 \%)$ & \\
\hline Widowed & $23(6.1 \%)$ & $3511(10.1 \%)$ & \\
\hline Divorced/separated & $52(13.8 \%)$ & $6218(17.8 \%)$ & \\
\hline Single & $57(15.2 \%)$ & ND & \\
\hline De facto & $25(6.6 \%)$ & ND & \\
\hline Other & $13(3.4 \%)$ & ND & \\
\hline Highest level of school completed & $n=275$ & $n=34047 \dagger$ & $<0.001$ \\
\hline Completed primary or lower & 78 & ND & \\
\hline Completed secondary grade 10 & $104(71 \%)$ & $15802(46.4 \%)$ & \\
\hline Completed secondary grade 12 & $42(29 \%)$ & $18245(53.6 \%)$ & \\
\hline Highest level of post-school qualifications & $n=275$ & $n=9447 \dagger$ & 0.38 \\
\hline TAFE/apprenticeship & $25(9.1 \%)$ & 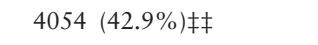 & \\
\hline University & $26(9.5 \%)$ & $5393(57.1 \%) \mathbb{S}$ & \\
\hline Employment $(15-85$ years +$) \dagger \dagger$ & $n=376$ & $n=49743 \dagger$ & $<0.001$ \\
\hline Employed & $122(32 \%)$ & $30652(61.6 \%)$ & \\
\hline Full time & $73(19.4 \%)$ & ND & \\
\hline Part time & $42(11.1 \%)$ & ND & \\
\hline Casual & $7(1.9 \%)$ & ND & \\
\hline Not in the workforce & $223(59 \%)$ & $17392(35 \%)$ & \\
\hline Home duties & $20(5.3 \%)$ & ND & \\
\hline Retired (aged pension/self-funded) & $118(31.3 \%)$ & ND & \\
\hline Disability support pension & $79(20.9 \%)$ & ND & \\
\hline Student & $6(1.6 \%)$ & ND & \\
\hline Unemployed & $32(8.5 \%)$ & $1699(3.4 \%)$ & \\
\hline Indigenous status & $n=377$ & $n=68835 \dagger$ & 0.30 \\
\hline Aboriginal person or Torres Strait Islander person & $27(7.2 \%)$ & $4074(5.9 \%)$ & \\
\hline Other & $350(92.8 \%)$ & $64761(94.1 \%)$ & \\
\hline Geographical remoteness & $n=378$ & $n=20701500 \ddagger$ & $<0.0001$ \\
\hline Major cities of Australia & $1(<0.1 \%)$ & $68.4 \%$ & \\
\hline Inner regional & $290(76.7 \%)$ & $19.7 \%$ & \\
\hline Outer regional & $84(22.2 \%)$ & $9.5 \%$ & \\
\hline Remote/very remote & $3(<0.8 \%)$ & $2.3 \%$ & \\
\hline Index of social disadvantage (SEIFA) & $n=378$ & $n=$ not available & $<0.0001$ \\
\hline Decile 1 and 2 (more disadvantage) & $18(4.8 \%)$ & $20 \%$ & \\
\hline Decile 3 and 4 & $273(72.2 \%)$ & $20 \%$ & \\
\hline Decile 5 and 6 & $84(22.2 \%)$ & $20 \%$ & \\
\hline Decile 7 and 8 & $1(0.03 \%)$ & $20 \%$ & \\
\hline Decile 9 and 10 (less disadvantage) & $2(0.05 \%)$ & $20 \%$ & \\
\hline
\end{tabular}

†Rockhampton (QLD) Statistical Division.

$\ddagger$ Based on 2006 national census data.

\Complete data not recorded for all clients.

IIFrom $\chi^{2}$ goodness-of-fit test.

††Comparison to the normative reference group could only be made using the broad employment categories of employed, not in the workforce and unemployed. Subgroups such as part time and full time only pertain to this study.

‡†Certificate, advanced diploma and diploma.

$\mathbb{S}$ Bachelor's degree or higher. SD, standard deviation; SEIFA, Socioeconomic Indexes for Areas; TAFE, Technical and Further Education Institute. 
TABLE 2: Disease prevalence as per diagnoses $(n=378)$

\begin{tabular}{|c|c|}
\hline Diagnoses reported by GPs & Number $(\%)$ \\
\hline Obesity & $255(67)$ \\
\hline Hypertension & $226(60)$ \\
\hline Osteoarthritis & $222(59)$ \\
\hline Hyperlipidaemia & $173(46)$ \\
\hline Diabetes mellitus (type 1 and type 2 ) & $174(46)$ \\
\hline Chronic back pain or sciatica & $175(46)$ \\
\hline $\begin{array}{l}\text { Mental health issues (including } \\
\text { depression, anxiety, bipolar disorder } \\
\text { and schizophrenia) }\end{array}$ & $135(36)$ \\
\hline Asthma & $114(30)$ \\
\hline Other cardiac disease & $111(29)$ \\
\hline Chronic obstructive pulmonary disease & $39(10)$ \\
\hline Chronic kidney disease & $36(10)$ \\
\hline $\begin{array}{l}\text { Cancer during the last } 5 \text { years (including } \\
\text { small skin cancers) }\end{array}$ & $75(20)$ \\
\hline Stroke & $25(7)$ \\
\hline $\begin{array}{l}\text { Thyroid disease (hyperthyroidism and } \\
\text { hypothyroidism) }\end{array}$ & $18(5)$ \\
\hline Congestive cardiac failure & $17(4)$ \\
\hline Rheumatoid arthritis & $7(2)$ \\
\hline $\begin{array}{l}\text { Other (including gout, GORD, } \\
\text { Parkinson's disease, intellectual } \\
\text { impairment, paraplegia, epilepsy, } \\
\text { Crohn's disease, post-polio syndrome } \\
\text { and diverticulitis) }\end{array}$ & $56(16)$ \\
\hline
\end{tabular}

GORD, gastro-oesophageal reflux disease; GP, general practitioner. overweight and normal/underweight people in the study sample (Table 6). The smoking status of the study sample was significantly different $(P=0.0021)$ compared with the National Survey of Mental Health and Wellbeing $^{12}$ sample, with the proportion of previous smokers higher but the proportion of current smokers lower than the comparison group (Table 6).

TABLE 3: Source and reason for client referral $(n=378)$

\begin{tabular}{lrl}
\hline Referral source & Number $(\%)$ \\
\hline General practitioner & $276(73.0)$ \\
Hospital & $33(8.6)$ \\
Cardiac Rehab Outreach Program & $51(13.4)$ \\
Other & $18(4.8)$ \\
\hline Reason for referral† & Number $(\%)$ \\
\hline Diabetes & $153(40.9)$ \\
Obesity & $65(17.2)$ \\
Osteoarthritis & $70(18.5)$ \\
Back pain & $47(12.4)$ \\
Hypertension & $29(7.7)$ \\
Cardiac conditions (other than hypertension) & $69(18.3)$ \\
Pain management & $21(5.6)$ \\
Other & $51(13.0)$ \\
& \\
\hline
\end{tabular}

†Patients might be referred for more than one condition.

TABLE 4: Health-related characteristics (without normative data comparison)

\begin{tabular}{lllll}
\hline Characteristics & $n$ & Mean \pm SD & Range & Confidence intervals \\
\hline Number of diagnosed conditions & 378 & $4.9 \pm 2.1$ & $1-12$ & $4.7,5.1$ \\
Number of prescribed medications & 377 & $5.7 \pm 3.7$ & $0-23$ & $5.3,6.1$ \\
\hline
\end{tabular}

SD, standard deviation.

TABLE 5: Health characteristics with comparison to normative reference data from health service: patient experience in Australia $(2009)^{13}$

\begin{tabular}{|c|c|c|c|c|c|}
\hline Characteristics & $n$ & $\begin{array}{l}\text { Study sample } \\
\text { Number }(\%)\end{array}$ & $\begin{array}{l}\text { Normative reference group } \\
\text { Number }(\%)\end{array}$ & $\begin{array}{l}\text { Difference in } \\
\text { proportions }(95 \% \mathrm{CI})\end{array}$ & $P$ value $\dagger$ \\
\hline Hospitalisation status & 378 & & $n=17300600$ & & 0.0001 \\
\hline Hospitalised in previous 12 months & & $164(43.3)$ & $2280000(13.2)$ & $0.30(0.25-0.35)$ & \\
\hline Not hospitalised in previous 12 months & & $214(56.7)$ & $15020600(86.8)$ & $0.41(0.36-0.46)$ & \\
\hline
\end{tabular}

†From $\chi^{2}$ goodness-of-fit test. CI, confidence interval. 
K.-A. FRAKES ET AL.

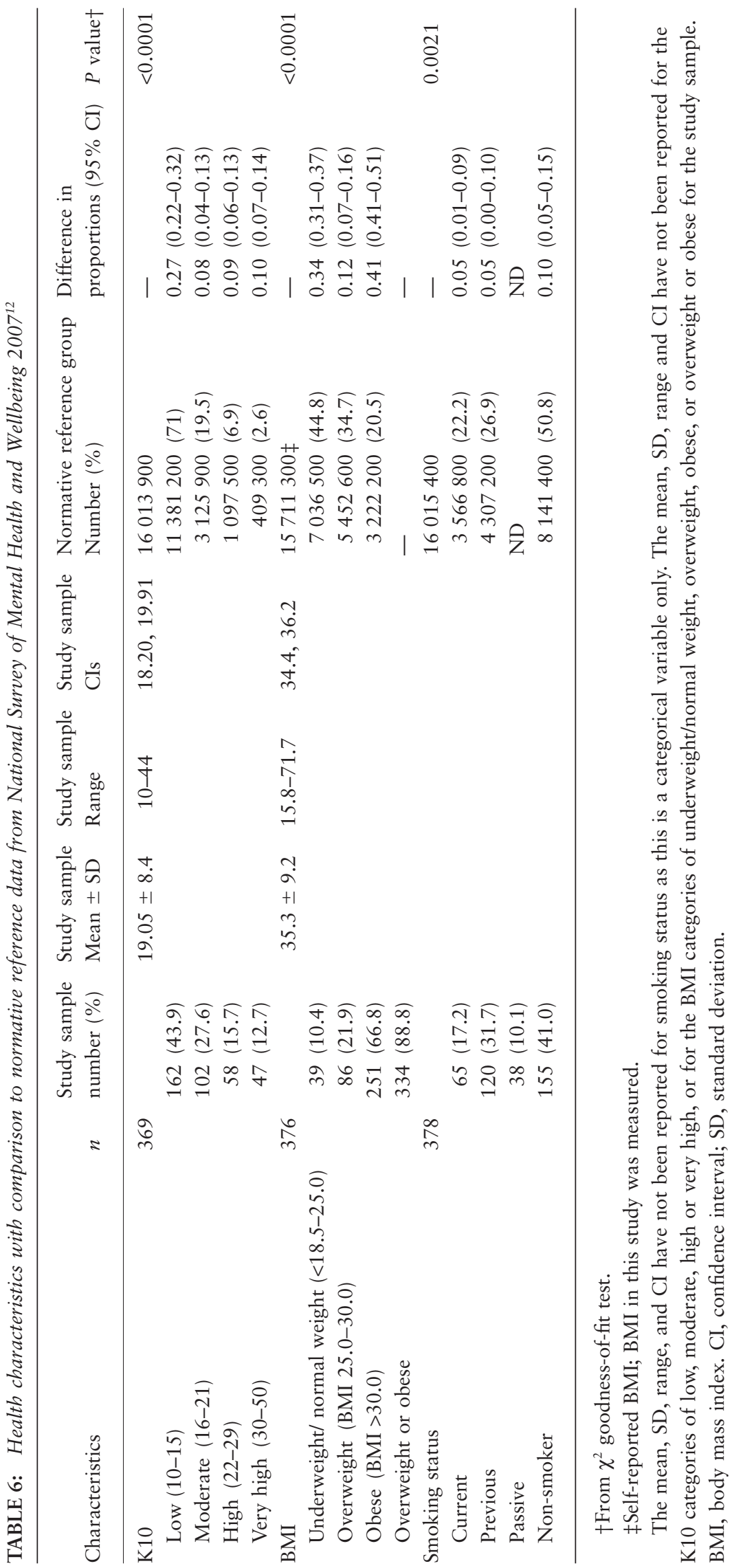

(C) 2013 The Authors Australian Journal of Rural Health @ National Rural Health Alliance Inc. 


\section{Discussion}

The profile of people attending the regional CAHP service in Central Queensland differs to that described in many chronic disease studies. Firstly, a diverse range of chronic diseases were seen compared with many chronic disease programs that focus on people with one particular chronic disease. Secondly, almost all of the people attending the clinic had multimorbidity (97\%); thus, the accumulated severity of their chronic disease(s) is likely to be higher than that reported for those with a single chronic disease in other studies.

Sociodemographic characteristics (age, unemployment, low education level and ethnicity) negatively impact on health outcomes including hospitalisation rates and quality of life for people with chronic diseases. ${ }^{14-16}$ In comparison with the Rockhampton Statistical Local Area (SLA) (the region in which the CAHP clinic is located), the CAHP patient group rated more poorly on the highest level of school education, employment and The Index of Social Disadvantage, suggesting more social disadvantage than the local population. For example, $8.5 \%$ of CAHP patients were unemployed compared with $3.4 \%$ for the Rockhampton SLA ${ }^{9}$, and $66.2 \%$ of CAHP patients nominated their highest level of education as secondary grade 10 or below (considered to be a low or very low level ${ }^{17}$ ) compared with $46.4 \%$ for the Rockhampton SLA. ${ }^{12,18}$ Although there was a higher percentage of patients who identified as an Aboriginal person and Torres Strait Islander in the study $(7.1 \%)$ compared with $5.9 \%$ of persons for the Rockhampton SLA, ${ }^{19}$ this difference was not significant.

Factors including multimorbidity, previous hospitalisations, multiple medication use, obesity, psychological distress and smoking have been linked to unfavourable chronic disease health outcomes. ${ }^{15,20,21}$ Almost half of the CAHP clinic patients reported being hospitalised in the last 12 months, $90 \%$ were taking multiple medications, $89 \%$ were overweight or obese, $12.7 \%$ had selfreported very high psychological distress and $48.9 \%$ were current or previous smokers. The $36 \%$ of patients who were reported to have mental health issues by their GPs corresponded to the proportion of patients with self-reported high or very high psychological distress $(28.4 \%)$. Based on these characteristics, the patients in this study are at high risk in terms of mortality and morbidity, placing a large burden on the health system.

The patient intake data presented in this report provides a valuable basis from which to plan and refine future service delivery at the regionally based CAHP clinic. For instance, the high percentage of patients $(90 \%)$ taking multiple medications highlights the importance of implementing pharmacy interventions to manage the side-effects experienced by patients taking these medications. Similarly, the high proportion of patients with very high psychological distress compared with the normative reference group highlights the need for adequate provision of mental health services.

Findings such as the high level of socioeconomic disadvantage compared with the local community and high levels of multimorbidity have implications for future research into the health outcomes of patients attending the clinic. For example, controlling for socioeconomic status and disadvantage is recommended in studies of intervention effectiveness, and considering the high percentage of multimorbidity, longitudinal study designs might be more appropriate than cross-sectional randomised, controlled trials. ${ }^{22}$

Limitations of the study include the retrospective design that limited the ability to control for bias and to reduce the amount of missing data. In addition, many measures of health-related characteristics were chosen for their clinical utility; however, the validity of some of these measures for chronic disease needs to be confirmed in chronic disease samples in future studies. It should also be pointed out that some of the differences between the study sample and normative reference groups might be accounted for by differences in the mode of administration of measures and other administrative variations. For example, the Kessler $10^{8}$ data were interviewer-administered in the study sample but selfadministered in the normative comparison group.

In summary, the data presented might serve as a guide to the CAHP clinic, other chronic disease services and future research with respect to the chronic disease patient characteristics that are important to consider.

\section{Acknowledgements}

The authors acknowledge significant funding and support from the Queensland Health 'Allied Health Workforce Advice and Coordination Unit', 'Clinical Education and Training Queensland' and Central Queensland Health Service District. The authors also acknowledge the significant contribution made by the following individuals: Ms Julie Hulcombe, Mr Rod Boddice, Ms Angela Swanston, Ms Anna Mickenbecker and the CAHP clinical staff. All contributors are affiliated with one of the aforementioned funding and support bodies.

\section{Author contributions}

K.A.F. and Z.T. conceived, designed, oversaw data collection and statistical analysis, contributed to discussion, and wrote and reviewed/edited the manuscript. L.D., J.T. and M.M. contributed to the discussion and reviewed/edited the manuscript. S.B. conceived and 
contributed to the discussion, and reviewed/edited the manuscript. All authors have read and approved the final manuscript.

\section{References}

1 Queensland Health The Health of Queenslanders. Third report of the Chief Health Officer. Brisbane, 2010.

2 Public Health Information Development Unit. Population health profile of the Capricornia Division of General Practice: supplement Population profile series no 84a. Adelaide, 2007.

3 National Health Priority Action Council (NPAC). National Chronic Disease Strategy. Australian Government Department of Health and Aging, Canberra, 2006.

4 Walker C. Chronic illness and consumer inequality: the impact of health costs on people with chronic illness. Australian Health Review 2007; 31: 203-210.

5 Charlson MA, Charlson RB, Peterson JC, Marinopoulos SS, Briggs WM, Hollenberg JP. The Charlson comorbidity index is adapted to predict costs of chronic disease in primary care patients. Journal of Clinical Epidemiology 2008; 61: 1234-1240.

6 Valderas JM, Starfield B, Sibbald B, Salisbury C, Roland M. Defining comorbidity: implications for understanding Health and Health Services. Annals of Family Medicine 2009; 7: 357-363.

7 Frakes KA, Tyack ZF, Miller M, Davies LA, Swanston A, Brownie S. The Capricornia Project: developing and implementing an interprofessional student-assisted allied health clinic. Clinical Education and Training (ClinEdQ), Queensland Health. Brisbane, Australia 2011. [Cited 28th February 2013]. Available from URL: www.health.qld.gov.au/ clinedq/Documents/capdocall.pdf

8 Kessler RC, Barker PR, Colpe LJ et al. Screening for serious mental illness in the general population. Archives of General Psychiatry 2003; 60: 184-189.

9 Australian Bureau of Statistics. Census of Population and Housing: Socioeconomic Indexes for Areas (SEIFA), Australia. Cat no.: 2033.0.55.001, released 26th March, 2008.

10 Australian Bureau of Statistics. Australian Social Trends, Cat no.: 4102.0. 2008.

11 Australian Bureau of Statistics. Census of Population and Housing: Rockhampton (QLD) Statistical Division. Cat no.: 2068. 2006.
12 Australian Bureau of Statistics. National Survey of Mental Health and Wellbeing: Summary of Results, Cat no.:4326.0. 2007.

13 Australian Bureau of Statistics. Health Services: Patient Experiences in Australia, Cat no.: 4839.0.55.001, 2009. 2009.

14 Bayliss EA, Ellis JL, Steiner JF. Subjective assessments of comorbidity correlate with quality of life health outcomes. Health and Quality of Life Outcomes 2005; 51: 1-8.

15 Muenchberger H, Kendall E. Predictors of preventable hospitalization in chronic disease: priorities for change. Journal of Public Health Policy 2010; 31: 150-163.

16 Panagiota G, Voulgari PV, Tsifetaki T, Drosos AA, Hyphantis T. Comparison of health-related quality of life and associated psychological factors between younger and older patients with established rheumatic disorders. Aging and Mental Health 2010; 14: 819-827.

17 Barbareschi G, Sanderman R, Lesman Leegte IL, Van Veldhuisen DV, Jaarsma T. Educational level and the quality of life of heart failure patients: a longitudinal study. Journal of Cardiac Failure 2011; 17: 47-53.

18 Hanley C, Mummery K. Final Sampling Report 2009 Central Queensland Social Survey. Population Research Laboratory, Institute for Health and Social Science Research, CQ University, Rockhampton, Australia. 2009.

19 Public Health Information Development Unit A Social Health Atlas of Australia, Queensland. 2010. [Cited 9 March 2012]. Available from URL: http://www. publichealth.gov.au/data/a-social-health-atlas-ofaustralia_-2010.html

20 Algul A, Ates MA, Semiz UB et al. Evaluation of general psychopathology, subjective sleep quality, and healthrelated quality of life in patients with obesity. International Journal of Psychiatry in Medicine 2009; 39: 297-312.

21 Christensen DB, Roth M, Trygstad T, Byrd J. Evaluation of a pilot medication therapy management project within the North Carolina State Health Plan. Journal of the American Pharmacists Association 2007; 47: 471-483.

22 Bettger JAP, Stineman MG. Effectiveness of multidisciplinary rehabilitation services in postacute care: state-ofthe-science. A review. Archives of Physical Medicine and Rehabilitation 2007; 88: 1526-1534. 